\title{
Global epidemiology of prediabetes - present and future perspectives
}

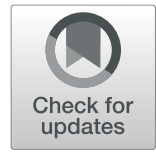

Ulrike Hostalek(1)

\begin{abstract}
Prediabetes is defined as an intermediate state of hyperglycaemia with glucose levels above the normal state but below the diagnostic levels of diabetes. It is increasingly recognised as an important metabolic state, as individuals with prediabetes are at high risk of developing overt diabetes and its associated complications. A better understanding of prediabetes could help with earlier identification, thereby allowing earlier intervention, potentially lowering the number of individuals who go on to develop diabetes. The definitions and screening criteria for prediabetes differ between guidelines published by different organisations, resulting in estimations of prevalence that can vary widely from one another. Despite these differences, these estimates suggest that the number of individuals affected by prediabetes is increasing rapidly in all areas of the world. This short review compares and contrasts the diagnostic criteria for screening of prediabetes, the impact of various glycaemic measures on prevalence estimates, and discusses current and future trends in the global prevalence estimates of prediabetes.
\end{abstract}

Keywords: Prediabetes, Diabetes, Global burden, Prevalence, Screening tools

\section{Background}

Prediabetes is increasingly recognised as an important metabolic state; as well as predisposing individuals to a high probability of future progression to diabetes, individuals with prediabetes are at increased risk of developing many of the pathologies normally associated with that disease, such as diabetic retinopathy, neuropathy, nephropathy and macrovascular complications [1].

In a cohort of individuals from the Diabetes Prevention Program (DPP), who were at high risk for developing diabetes, the prevalence of diabetic retinopathy was $7.9 \%$ [2]. In a different study, the prevalence of peripheral neuropathy was higher in those with prediabetes than in those with normal glucose tolerance, and was similar to that in participants with recently diagnosed diabetes [3]. An association between prediabetes and increased risk of chronic kidney disease (CKD) has also been reported, based on results from a meta-analysis [4]. Another meta-analysis showed that, compared with normoglycaemic individuals, there is an increased risk of cardiovascular disease, coronary heart disease, stroke and all-cause mortality in those with prediabetes [5]. In

Correspondence: Ulrike.gottwald-hostalek@merckgroup.com

Global Medical Affairs, Merck KGaA, Frankfurterstr. 250, 64293 Darmstadt, Germany

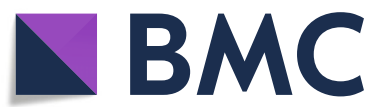

addition, elevated plasma glucose levels indicative of prediabetes in early pregnancy are associated with increased risk of adverse pregnancy outcomes, and may also lead to gestational diabetes in later pregnancy [6].

Besides these associated complications, the view that prediabetes is a distinct pathological condition to diabetes is supported by the recent inclusion of codes specifically listing 'prediabetes' as a separate billable condition in the International Classification of Diseases, 10th Revision, Clinical Modification (ICD-10-CM) [7].

Prediabetes will progress to overt type 2 diabetes (T2DM) in approximately $25 \%$ of subjects within $3-5$ years, and as many as $70 \%$ of individuals with prediabetes will develop overt diabetes within their lifetime $[1,8]$. As a chronic disease, the long-term implications of diabetes contribute to poor quality of life and greatly increase healthcare expenditure [9]. Prediabetes may however be reversible, through the implementation of lifestyle modification programmes based around the adoption of healthier diet and increased levels of physical activity $[10,11]$. Where lifestyle modifications are ineffective, medications such as metformin or acarbose may be indicated $[10,11]$. A commonly cited statistic states that 1:3 Americans has prediabetes, and that 90\% are not aware of their condition, [12] but how does this

(C) The Author(s). 2019 Open Access This article is distributed under the terms of the Creative Commons Attribution 4.0 International License (http://creativecommons.org/licenses/by/4.0/), which permits unrestricted use, distribution, and reproduction in any medium, provided you give appropriate credit to the original author(s) and the source, provide a link to the Creative Commons license, and indicate if changes were made. The Creative Commons Public Domain Dedication waiver (http://creativecommons.org/publicdomain/zero/1.0/) applies to the data made available in this article, unless otherwise stated. 
compare to estimates derived from other studies conducted in other countries? This short review assesses the current and future trends in the global prevalence of prediabetes.

\section{Defining prediabetes}

Prediabetes is a chronic metabolic condition where blood glucose levels are above the upper threshold considered normal but below the threshold for a diagnosis of diabetes $[1,8]$. Importantly, the diagnostic criteria and terminology associated with prediabetes vary considerably between organisations, and care must be taken when interpreting and describing prevalence and incidence data (Table 1) $[7,9,13]$.

ADA, American Diabetes Association; FPG, fasting plasma glucose; $\mathrm{HbA}_{1 \mathrm{C}}$, glycated haemoglobin; IDF, International Diabetes Federation; IFG, impaired fasting glucose; IGT, impaired glucose tolerance; ND, not defined; OGTT, oral glucose tolerance test; PG, plasma glucose; WHO, World Health Organization.

Both the World Health Organization (WHO) and the American Diabetes Association (ADA) provide guidance on screening for prediabetes based on assessment of impaired glucose tolerance (IGT) and impaired fasting glucose (IFG) levels. While the defined thresholds for IGT are common to both guidelines, the ADA recommend a lower threshold for IFG relative to the WHO guidelines. $[7,13]$ This move was an attempt to improve the concordance of prevalence estimates between IFG and IGT, which when defined using WHO thresholds can differ considerably from each other. The criteria used by the WHO were derived not on overall prevalence, but to reflect the relative likelihood of progression to overt T2DM; IFG, reflective of hepatic insulin resistance is considered the more important predictor of diabetes risk than skeletal muscle insulin resistance described by IGT [14].

IFG is assessed based on the fasting plasma glucose (FPG) level, and IGT using the 2-h plasma glucose during a $75 \mathrm{~g}$ oral glucose tolerance test (OGTT). The ADA have also recommended the assessment of glycated haemoglobin $\left(\mathrm{HbA}_{1 \mathrm{c}}\right)$ to screen for prediabetes, $[15,16]$ however, this view is not endorsed by the WHO. These tests do not necessarily detect prediabetes in the same individuals, and according to ADA guidance, abnormal results from any of the tests is sufficient for prediabetes diagnosis. $\mathrm{HbA}_{1 \mathrm{C}}$ is considered by many as a more reliable test of impaired glucose homeostasis as it is reflective of steady-state blood glucose levels over a period of several months, so is not prone to day-to-day variability that may confound assessment of IGT or IFG [15]. It is also a more convenient screening test than FPG or OGTT, as fasting is not required [13]. However, the availability of $\mathrm{HbA}_{1 \mathrm{C}}$ testing may be limited in developing countries [13]. As an indirect measure of average blood glucose levels, $\mathrm{HbA}_{1 \mathrm{C}}$ may be affected by ethnicity and haemoglobin variants, $[13,17]$ although most assays used in the US are unaffected by common variants [13]. In the DPP, African Americans had higher $\mathrm{HbA}_{1 \mathrm{C}}$ levels than Caucasians, despite similar fasting and 2-h glucose levels [18]. In addition, it is worth noting that key diabetes prevention studies, such as the DPP and its long-term follow-up Diabetes Prevention Program Outcomes Study (DPPOS), which enrolled patients at high risk of developing diabetes, did not use $\mathrm{HbA}_{1 \mathrm{C}}$ as an inclusion criterion $[19,20]$. When DPP was initiated, $\mathrm{HbA}_{1 \mathrm{C}}$ was not an established measure of glycaemic control; however, additional analyses of the data have since been conducted, and baseline $\mathrm{HbA}_{1 \mathrm{C}}$ was shown to be a strong predictor of diabetes incidence [21].

It is unclear which diagnostic criteria are the most appropriate for identifying people with prediabetes, but as mentioned above, the lower threshold for IFG in the ADA guidelines compared with the $\mathrm{WHO}$ and the International Diabetes Federation (IDF) guidelines improves the parity between the number of people identified by IFG and IGT. The ADA recommendations are regularly updated with the most recent scientific data and may be considered more globally accepted than the other guidelines.

With a range of criteria available for prediabetes identification, it is not surprising that populations with prediabetes identified by each method vary widely and have limited overlap [17]. These differences in screening criteria for prediabetes may result in incorrect diagnoses, leading to some people being unnecessarily treated, and others left without treatment to prevent or delay the onset of overt type 2

Table 1 Diagnostic criteria for prediabetes

\begin{tabular}{llll}
\hline Criterion & ADA [13] & WHO [7] & IDF [9] \\
\hline Terminology & Prediabetes & Intermediate hyperglycaemia & Impaired glucose tolerance \\
IGT (assessed using 2-h PG during 75 g OGT) & $7.8-11.0 \mathrm{mmol} / \mathrm{L}(140-199 \mathrm{mg} / \mathrm{dL})$ & & \\
IFG (assessed using FPG) & $5.6-6.9 \mathrm{mmo} / \mathrm{L}(100-125 \mathrm{mg} / \mathrm{dL})$ & $6.1-6.9 \mathrm{mmol} / \mathrm{L}(110-125 \mathrm{mg} / \mathrm{dL})$ & \\
$\mathrm{HbA}_{1 \mathrm{C}}$ & $5.7-6.4 \%(39-47 \mathrm{mmol} / \mathrm{mol})$ & $\mathrm{ND}$ & \\
\hline
\end{tabular}


diabetes. Similarly, it is difficult to assess the global burden of prediabetes.

\section{Prevalence of prediabetes}

Prevalence estimates of prediabetes reported in the literature vary greatly, due to the diagnostic criteria used, the choice of test and due to the populations being studied (Table 2). The lower cut-off defined by the ADA guidelines lead to much higher prevalence rates compared with those defined by WHO guidelines; in a cohort of 1547 American adults without diabetes, changing the lower IFG threshold from $110 \mathrm{mg} / \mathrm{dL}$ to $100 \mathrm{mg} / \mathrm{dL}$ resulted in an increase in prediabetes prevalence from 19.8 to $34.6 \%$ [22]. A large meta-analysis of studies that reported prevalence in Caucasian and Asian cohorts estimated IFG prevalence at $36.0 \%$ using WHO guidelines and $53.1 \%$ using ADA guidelines. By contrast, the same meta-analysis described similar prevalence rates for patients who have both IFG and IGT; $15.8 \%$ for WHO and $20.2 \%$ for ADA guidelines [14].

As mentioned above, $\mathrm{HbA}_{1 \mathrm{C}}$ is considered by many as a more reliable test of impaired glucose homeostasis. A study of 1542 healthy Swiss adults identified prediabetes in $30.9 \%$ of the population; of these $79.9 \%$ were identified on the basis of $\mathrm{HbA}_{1 \mathrm{C}}, 9.9 \%$ on the basis of FPG, and $10.3 \%$ on the basis of both of these ADA guideline criteria ( $\mathrm{HbA}_{1 \mathrm{C}}$ and IFG) [23].

As would be expected, prevalence estimates vary widely depending on the diagnostic test used, even within the same study population. In some cases, prediabetes diagnosis is based on one criterion (e.g. IGT), while others evaluate results from more than one test. According to the ADA guidelines, an abnormal finding of any of the three criteria (IFG, IGT and $\mathrm{HbA}_{1 \mathrm{C}}$ ) is sufficient to confirm prediabetes [13]. Relying on one test may underestimate prevalence.

\section{Global variability in prediabetes prevalence}

The complexities of prediabetes identification, described above, can make it challenging to gain on overview of relative prediabetes prevalence from the literature.
However, the IDF have published a comprehensive picture of the current and future trends of prediabetes prevalence based on IGT in individuals aged $20-79$ years (Fig. 1) [9]. The global prevalence of IGT was estimated at $7.3 \%$ of the adult population in 2017, equivalent to 352.1 million individuals. By 2045 the prevalence is anticipated to increase to $8.3 \%$ of the global adult population, equivalent to an estimated 587 million individuals. There is no significant difference of prevalence in men and women, and around half of all individuals with IGT are aged under 50 years [9]. Unadjusted regional prevalence is currently highest in the North America and Caribbean (15.4\%) and Central and South America (10.0\%) IDF regions, and lowest in the South East Asia (3.0\%) and European (5.5\%) regions [9]. It should be noted that these estimates are based on IGT only, so prevalence may be higher if additional criteria were taken into consideration.

\section{Factors that affect prevalence rates of prediabetes}

A number of epidemiological studies have demonstrated a clear relationship between ethnicity and likelihood of prediabetes; African American, Native American, South Asian and Hispanic have all been shown to have an increased risk of having prediabetes compared with their Caucasian counterparts [14, 24].

A complex interaction of further factors that include life expectancy, socioeconomic status, wealth, access to healthcare services, levels of education, exposure to disease/public health awareness initiatives, and regional levels of obesity influence prevalence rates [25-27]. As populations become more urbanised, become wealthier, gain better access to nutrition, healthcare and education, and live longer, rates of prediabetes are expected to increase. These increases are expected to be more pronounced in developing rather than in developed countries as lifestyles become more 'westernised'.

\section{Conclusions}

The reported prevalence for prediabetes vary widely within the literature, reflecting the heterogeneity of both

Table 2 Variation in estimated prediabetes prevalence in the literature

\begin{tabular}{|c|c|c|c|c|c|c|c|}
\hline \multirow[t]{2}{*}{ Author } & \multirow{2}{*}{$\begin{array}{l}\text { Guideline } \\
\text { criteria } \\
\text { used }\end{array}$} & \multicolumn{6}{|c|}{ Estimated prevalence (\%) } \\
\hline & & IFG or IGT & IFG & IGT & IFG and IGT & $\mathrm{HbA}_{1 \mathrm{C}}$ & $\mathrm{HbA}_{1 \mathrm{C}}$ and IFG \\
\hline \multirow[t]{2}{*}{ Karve [22] } & $\mathrm{ADA}^{\mathrm{a}}$ & 19.8 & 4.5 & 11.8 & 3.5 & - & - \\
\hline & ADA $†$ & 34.6 & 19.4 & 5.4 & 9.8 & - & - \\
\hline \multirow[t]{2}{*}{ Yip [14] } & ADAt & - & 53.1 & 23.8 & 20.2 & - & - \\
\hline & WHO & - & 36.0 & 45.5 & 15.8 & - & - \\
\hline Blum [23] & ADAt & - & 3.0 & - & - & 24.7 & 3.2 \\
\hline
\end{tabular}

a1997 guidelines, FPG: 6.1-6.9 mmol/L (110-125 mg/dL); †post 2003 guidelines, FPG: 5.6-6.9 mmol/L (100-125 mg/dL) ADA American Diabetes Association, FPG Fasting plasma glucose, $\mathrm{HbA}_{1 \mathrm{C}}$, glycated haemoglobin; IFG Impaired fasting glucose, IGT Impaired glucose tolerance, WHO World Health Organization 


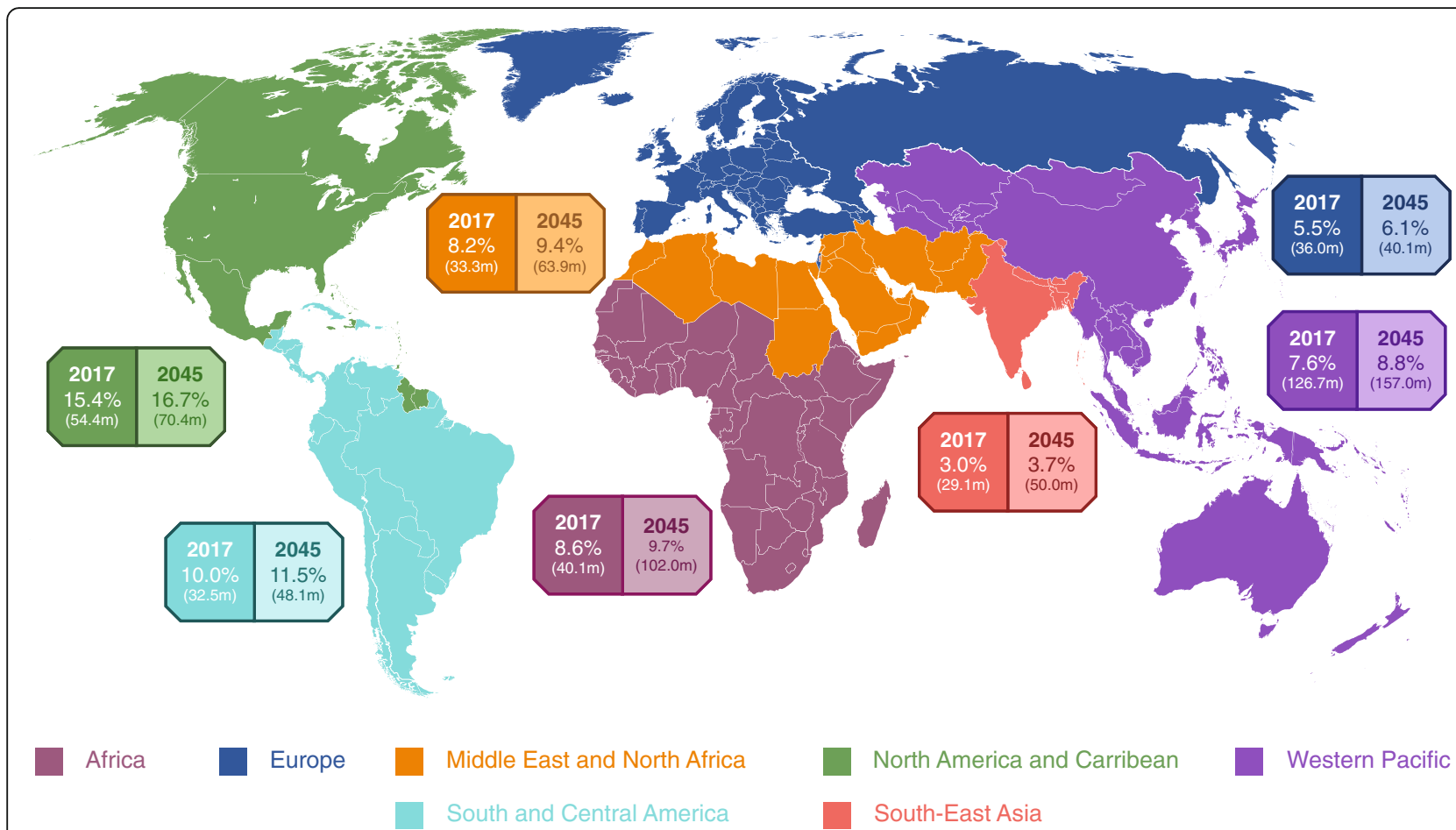

Fig. 1 Global prevalence estimates of IGT by IDF region [9]. Data source: IDF Diabetes Atlas - 8th Edition. Percentages represent unadjusted regional prevalence estimates. Numbers in parentheses represent the estimated number of individuals affected by IGT in each region. Prevalence estimates calculated by the IDF using a generalised linear regression model. A variety of country-level data sources were included, mostly from peer-reviewed journals and national health surveys. The studies selected were required to meet rigorous inclusion criteria based on input from international experts. Prevalence in countries without original data available was extrapolated based on data collected from similar countries, based on ethnicity, income level and geography. IDF, International Diabetes Federation; IGT, impaired glucose tolerance; m, million

the methods used to define the condition, and of the characteristics of the populations themselves. What is clear, however, is that the prevalence of prediabetes is increasing rapidly in all parts of the world. Action is required to halt this increase, and to avoid the future diabetes epidemic that currently threatens to overwhelm global healthcare provisions.

\section{Abbreviations \\ ADA: American Diabetes Association; CKD: Chronic kidney disease; DPP: Diabetes Prevention Program; DPPOS: Diabetes Prevention Program Outcomes Study; FPG: Fasting plasma glucose; $\mathrm{HbA}_{1}$ : Glycated haemoglobin; ICD-10-CM: International Classification of Diseases, 10th Revision, Clinical Modification; IDF: International Diabetes Federation; IFG: Impaired fasting glucose, IGT, impaired glucose tolerance; m: Million; ND: Not defined; OGTT: Oral glucose tolerance test; PG: Plasma glucose; T2DM: Type 2 diabetes; WHO: World Health Organization}

\section{Acknowledgements}

Medical writing support was provided by Andrew Smith, PhD, of Fishawack Communications $\mathrm{GmbH}$, funded by Merck KGaA.

\section{Funding}

UH is an employee of Merck KGaA, Darmstadt, Germany. Preparation of this manuscript was funded by Merck KGaA, Darmstadt, Germany.

Availability of data and materials Not applicable.

\section{Authors' contributions}

UH conceived, critically reviewed and approved the manuscript for submission.

\section{Ethics approval and consent to participate}

Not applicable.

\section{Consent for publication}

Not applicable.

\section{Competing interests}

Not applicable.

\section{Publisher's Note}

Springer Nature remains neutral with regard to jurisdictional claims in published maps and institutional affiliations.

Received: 9 January 2019 Accepted: 1 May 2019

Published online: 09 May 2019

\section{References}

1. Tabak AG, Herder C, Rathmann W, Brunner EJ, Kivimaki M. Prediabetes: a high-risk state for diabetes development. Lancet. 2012;379:2279-90.

2. Diabetes Prevention Program Research Group. The prevalence of retinopathy in impaired glucose tolerance and recent-onset diabetes in the diabetes prevention program. Diabet Med. 2007;24:137-44.

3. Lee CC, Perkins BA, Kayaniyil S, Harris SB, Retnakaran R, Gerstein HC, Zinman B, Hanley AJ. Peripheral neuropathy and nerve dysfunction in individuals at high risk for type 2 diabetes: the PROMISE cohort Diabetes Care. 2015;38:793-800. 
4. Echouffo-Tcheugui JB, Narayan KM, Weisman D, Golden SH, Jaar BG. Association between prediabetes and risk of chronic kidney disease: a systematic review and meta-analysis. Diabet Med. 2016;33:1615-24.

5. Huang Y, Cai X, Mai W, Li M, Hu Y. Association between prediabetes and risk of cardiovascular disease and all cause mortality: systematic review and meta-analysis. Bmj. 2016:355:15953.

6. Metzger BE, Lowe LP, Dyer AR, Trimble ER, Chaovarindr U, Coustan DR, Hadden DR, McCance DR, Hod M, McIntyre HD, et al. Hyperglycemia and adverse pregnancy outcomes. N Engl J Med. 2008;358:1991-2002.

7. ICD-10-CM codes [https://www.icd10data.com].

8. Camila Furtado de Souza, Jorge Luiz Gross, Fernando Gerchman, Piglet CB: pre-diabetes: diagnosis, evaluation and treatment of chronic complications. Arq Bras Endocrinol Metab 2012, 56.

9. International diabetes federation: IDF diabetes atlas - 8th edition, 2017.

10. 2017 IDF: IDF clinical practice recommendations for managing type 2 diabetes in primary care.

11. American Diabetes Association. 3. Prevention or delay of type 2 diabetes: standards of medical Care in Diabetes-2019. Diabetes Care. 2019, 42:S29-33.

12. Centers for Disease Control and Prevention; https://www.cdc.gov/diabetes/ data/statistics-report/prevalence.html

13. American Diabetes Association. 2. Classification and diagnosis of diabetes: standards of medical Care in Diabetes-2019. Diabetes Care. 2019, 42:S13-28.

14. Yip WCY, Sequeira IR, Plank LD, Poppitt SD. Prevalence of pre-diabetes across ethnicities: a review of impaired fasting glucose (IFG) and impaired glucose tolerance (IGT) for classification of Dysglycaemia. Nutrients. 2017;9.

15. Sequeira IR, Poppitt SD: HbA1c as a marker of prediabetes: a reliable screening tool or not? Insights Nutr Metabol 2017, 1:21-29.

16. Yudkin JS, Montori VM. The epidemic of pre-diabetes: the medicine and the politics. Bmj. 2014;349:g4485.

17. Barry E, Roberts S, Oke J, Vijayaraghavan S, Normansell R, Greenhalgh T. Efficacy and effectiveness of screen and treat policies in prevention of type 2 diabetes: systematic review and meta-analysis of screening tests and interventions. BMJ. 2017;356.

18. Herman WH, Ma Y, Uwaifo G, Haffner S, Kahn SE, Horton ES, Lachin JM, Montez MG, Brenneman T, Barrett-Connor E. Differences in A1C by race and ethnicity among patients with impaired glucose tolerance in the diabetes prevention program. Diabetes Care. 2007;30:2453-7.

19. Knowler WC, Fowler SE, Hamman RF, Christophi CA, Hoffman HJ, Brenneman AT, Brown-Friday JO, Goldberg R, Venditti E, Nathan DM. 10year follow-up of diabetes incidence and weight loss in the diabetes prevention program outcomes study. Lancet. 2009;374:1677-86.

20. Knowler WC, Barrett-Connor E, Fowler SE, Hamman RF, Lachin JM, Walker EA, Nathan DM. Reduction in the incidence of type 2 diabetes with lifestyle intervention or metformin. N Engl J Med. 2002;346:393-403.

21. Diabetes Prevention Program Research Group. HbA1c as a predictor of diabetes and as an outcome in the diabetes prevention program: a randomized clinical trial. Diabetes Care. 2015;38:51-8.

22. Karve A, Hayward RA. Prevalence, diagnosis, and treatment of impaired fasting glucose and impaired glucose tolerance in nondiabetic U.S. adults. Diabetes Care. 2010:33:2355-9.

23. Blum J, Aeschbacher S, Schoen T, Bossard M, Pumpol K, Brasier N, Risch M, Risch L, Conen D. Prevalence of prediabetes according to hemoglobin A1c versus fasting plasma glucose criteria in healthy adults. Acta Diabetol. 2015; $52: 631-2$

24. Sentell TL, He G, Gregg EW, Schillinger D. Racial/ethnic variation in prevalence estimates for United States prediabetes under alternative 2010 American Diabetes Association criteria: 1988-2008. Ethn Dis. 2012;22:451-8.

25. Anjana RM, Deepa M, Pradeepa R, Mahanta J, Narain K, Das HK, Adhikari P, Rao PV, Saboo B, Kumar A, et al. Prevalence of diabetes and prediabetes in 15 states of India: results from the ICMR-INDIAB population-based crosssectional study. Lancet Diabetes Endocrinol. 2017:5:585-96.

26. Yisahak SF, Beagley J, Hambleton IR, Narayan KM. Diabetes in North America and the Caribbean: an update. Diabetes Res Clin Pract. 2014;103:223-30

27. Akter S, Rahman MM, Abe SK, Sultana P. Prevalence of diabetes and prediabetes and their risk factors among Bangladeshi adults: a nationwide survey. Bull World Health Organ. 2014;92:204-213, 213a.

\section{Ready to submit your research? Choose BMC and benefit from:}

- fast, convenient online submission

- thorough peer review by experienced researchers in your field

- rapid publication on acceptance

- support for research data, including large and complex data types

- gold Open Access which fosters wider collaboration and increased citations

- maximum visibility for your research: over $100 \mathrm{M}$ website views per year

At BMC, research is always in progress.

Learn more biomedcentral.com/submissions 